\title{
An urban environmental monitoring and information system
}

\author{
J. F. G. Mendes ${ }^{1,2}$, L. T. Silva ${ }^{1}$, P. Ribeiro ${ }^{1} \&$ A. Magalhães ${ }^{2}$ \\ ${ }^{I}$ Department of Civil Engineering, University of Minho, Portugal \\ ${ }^{2}$ Innovation Point - S.A., Portugal
}

\begin{abstract}
Evaluating, monitoring and informing about urban environmental quality has become a main issue, particularly important when considered as a decisionmaking tool that contributes to more habitable and sustainable cities. Following a tendency observed in other European cities, the city of Braga (Portugal) has decided to create an infrastructure for environmental data acquisition and a webbased platform as a public information system. Some of the innovations introduced in this new platform include the use of mobile instrumented units, the extensive use of simulation software to create long-term pollution (air and noise) maps, and the presentation of the information through a geographical interface developed over Google Maps technology. This paper discusses some of the critical aspects regarding the conceptual design of such an information system, and presents the actual information system developed for Braga, named SmarBRAGA.
\end{abstract}

Keywords: environmental monitoring, public information, air pollution, noise.

\section{Introduction}

The growth of the world's population has been followed by the increase of the population living in urban areas, which very often results in additional pressures over space, ecosystems, infrastructures, facilities and the way of life.

Domestic and industrial sources, and mainly motorised traffic, are responsible for pollutant emissions and noise which decisively affect life in today's cities [1]. In this context, evaluating and monitoring the urban environmental quality has become a main issue, particularly important when considered as a decisionmaking tool that contributes to more liveable and sustainable cities. 
Noise caused by road traffic is the nuisance most often mentioned by roadside residents. Urban air pollution became one of the main factors of degradation of the quality of life in cities, mainly in roadside areas. This problem tends to worsen due to the unbalanced development of urban spaces and the significant increase of mobility and road traffic. The quantitative evaluation of traffic noise levels and air pollutant concentrations is the basis upon which noise and air pollution control policies stand [2].

Braga is a mid-sized city located in the North of Portugal, where an environmental program was developed leading to its integration in the BragaDigital project funded by EU through the "POS-Conhecimento" program. Within this program, the urban pollution assessment and a public information system were considered a priority.

The project, named SmarBRAGA, obtained public funding resulting on its development by the private company Innovation Point, in close collaboration with the University of Minho and the municipal enterprise AGERE.

\section{The conceptual model}

The aim of a monitoring and information system is to support the formulation of control strategies and, additionally, to inform the population about the urban environmental situation. In this paper we focus on the information objective.

The critical aspects of such a monitoring and information system are discussed in the following sections and include: i) the quality label-based information; ii) the long-term environmental maps versus the pointmeasurements; iii) the importance of motor traffic as the main pollution source; iv) the selection of air pollution and noise descriptors; and v) the algorithm which generates environmental quality labels.

\subsection{Monitoring and informing by means of quality labels (green to red)}

No matter how the environmental measurements are acquired, numerical information needs to be processed and formatted in a way that can be easily understood to the public.

In the case described in this paper, three algorithms were developed and used to convert the measurements taken on a regular basis into a classification scale of quality labels (green to red [left to right]), as represented in Table 1.

Table 1: $\quad$ Urban pollution indicators.

\begin{tabular}{|c|c|c|c|c|}
\hline \multicolumn{5}{|c|}{ Air Quality, Urban Noise and Heat Index } \\
\hline & & & & \\
\hline Very Good & Good & Moderate & Poor & Very Poor \\
\hline
\end{tabular}




\subsection{Long-term maps versus point-measurements}

Point-measurements of noise and air pollution data are very useful inputs to understand and evaluate the environmental quality of an urban area. However, these values are strongly linked with a particular location in a given measurement time, which means that the information is limited and has to be interpreted in that sense. Further extensions or conclusions require other tools, namely the use of simulation software based on mathematical models.

A comprehensive urban environmental information system for the public must include long-term pollution (or quality) maps covering the city and pointmeasurements. The first reflect an "average" situation of the environmental quality over the city, useful whenever a citizen needs an overview on a particular part of the city, for instance in the case he is selecting where to buy a flat. The last is useful whenever a citizen wants to have an up-to-date measurement of environmental local conditions, for instance in the case he is deciding whether to go for a bike tour.

Long-term horizontal pollution maps are developed through the modelling of the dispersion of air pollution in built-up urban areas and integrate all the parameters which influence the dispersion, such as topography and meteorological conditions. For the noise simulation, the situation is similar, but the mathematical model is obviously a specific one.

As the main source of pollution is typically the traffic, a campaign of traffic counts across the city is required, which should be carried out in at least one typical weekday. Ideally, a traffic count information system should be maintained in order to maintain frequent updates.

\subsection{The importance of traffic data}

The evaluation of urban environmental quality is closely related with noise and air pollution descriptors, which are intrinsically correlated with the characteristics of traffic. Characterization of road traffic is of extreme importance in order to deliver accurate outputs of long-term air and noise pollution. This must be done considering an all-day ( 24 hours) period to obtain a complete and reliable idea of the traffic flows on the road network of a city. For this reason, traffic counts must be well-planned, based on the city road hierarchy, and a complete profile of the traffic behaviour during a day for all road categories must be achieved. Furthermore, speed must be evaluated, or at least an average standard speed applied to each road category, as well as the decomposition of traffic in different categories, such as trucks, cars, buses, twowheelers, among others. The percentage of heavy-vehicles is one of the most important factors for modelling long-term environmental noise and air pollution.

\subsection{Selection of air pollution and noise descriptors}

Domestic and industrial sources and mainly motorised traffic are responsible for pollutant emissions and noise which decisively affect living in today's cities $[3,4]$. 
The combustion of hydrocarbon fuel in the air generates mainly carbon dioxide $\left(\mathrm{CO}_{2}\right)$ and water $\left(\mathrm{H}_{2} \mathrm{O}\right)$. However, the combustion engines are not totally efficient, which means that the fuel is not totally burned. In this process the product of the combustion is more complex and could be composed by hydrocarbons and other organic compounds, carbon monoxide (CO) and particles (PM) containing carbon and other pollutants [5]. On the other hand, the combustion conditions - high pressures and temperatures - originate partial oxidation of the nitrogen present in the air and in the fuel, forming oxides of nitrogen ( $N O+\mathrm{NO} 2)$ conventionally designated by NOx. Many of the atmospheric pollutants once emitted from the road vehicles react with the air components or react together and form the so-called secondary pollutant (for instance the O3)[6].

The descriptors typically adopted to assess urban air pollution are: Nitrogen Dioxide $\left(\mathrm{NO} 2, \mu \mathrm{g} / \mathrm{m}^{3}\right)$, Ozone $\left(\mathrm{O} 3, \mu \mathrm{g} / \mathrm{m}^{3}\right)$, Carbon Monoxide $\left(\mathrm{CO}, \mathrm{mg} / \mathrm{m}^{3}\right)$ and Particulate Matter $\left(\mathrm{PM} 10, \mu \mathrm{g} / \mathrm{m}^{3}\right)$. For specific purposes others like $\mathrm{CO}_{2}$ and COV are as well evaluated.

Regarding noise, the classical long-term map descriptor is the A-weighted Equivalent Continuous Sound Level - Leq(A) for three time periods: Lday (daynoise indicator; period between $7 \mathrm{~h} 00$ am and $8.00 \mathrm{pm}$ ); Levening (evening-noise indicator; period between $8 \mathrm{~h} 00 \mathrm{pm}$ and $11.00 \mathrm{pm}$ ); and Lnight (night-time noise indicator; period between $11 \mathrm{~h} 00 \mathrm{pm}$ and $7 \mathrm{~h} 00 \mathrm{am}$ ). Additionally, an aggregated descriptor is used, the Lden (day-evening-night). These descriptors are the ones adopted and recommended by the European Directives and the national legislation of most of the European countries.

\subsection{Quality labels algorithm}

Quality labels are generated daily for air quality, urban noise and heat index, based on a multicriteria algorithm which combines normalized values of pointmeasurements.

The calculation of the air quality label takes into account hourly averages of nitrogen dioxide (NO2), ozone (O3), carbon monoxide $(\mathrm{CO})$ and particulate matter (PM10), for which the quality levels to be combined are presented in Table 2 .

Table 2: $\quad$ Air quality and noise.

\begin{tabular}{|c|c|c|c|}
\hline \multicolumn{4}{|c|}{ Air quality } \\
\hline $\begin{array}{c}\mathbf{C O} \\
\left(\mathbf{m g} / \mathbf{m}^{\mathbf{3}}\right)\end{array}$ & $\begin{array}{c}\mathbf{N O 2} \\
\left(\boldsymbol{\mu g} / \mathbf{m}^{\mathbf{3}}\right)\end{array}$ & $\begin{array}{c}\mathbf{O 3} \\
\left(\boldsymbol{\mu g} / \mathbf{m}^{\mathbf{3}}\right)\end{array}$ & $\begin{array}{c}\mathbf{P M 1 0} \\
\left(\boldsymbol{\mu g} / \mathbf{m}^{\mathbf{3}}\right)\end{array}$ \\
\hline$]-, 4.9]$ & ]$-, 99.9]$ & ]$-, 59.9]$ & ]$-, 19.9]$ \\
\hline$[5.0,6.9]$ & {$[100.0,139.9]$} & {$[60.0,119.9]$} & {$[20.0,34.9]$} \\
\hline$[7.0,8.4]$ & {$[140.0,199.9]$} & {$[120.0,179.9]$} & {$[35.0,49.9]$} \\
\hline$[8.5,9.9]$ & {$[200.0,399.9]$} & {$[180.0,239.9]$} & {$[50.0,119.9]$} \\
\hline$[10.0,+[$ & {$[400.0,+[$} & {$[240.0,+[$} & {$[120.0,+[$} \\
\hline
\end{tabular}

\begin{tabular}{|c|}
\hline Urban noise \\
\hline $\begin{array}{c}\text { Leq } \\
\text { (dBA) }\end{array}$ \\
\hline ] -, 55] \\
\hline ] $55,62.5$ ] \\
\hline ] $62.5,67.5$ ] \\
\hline ] $67.5,75$ ] \\
\hline ] $75,+]$ \\
\hline
\end{tabular}

\begin{tabular}{|c|}
\hline Classification \\
\hline Very Good (4) \\
\hline Good (3) \\
\hline Moderate (2) \\
\hline Poor (1) \\
\hline Very Poor (0) \\
\hline
\end{tabular}


Table 3: $\quad$ Heat index (values in ${ }^{\circ} \mathrm{C}$ ).

\begin{tabular}{|c|c|c|c|c|c|}
\hline Month & $\begin{array}{l}\text { Very } \\
\text { Good }\end{array}$ & Good & Moderate & Poor & Very Poor \\
\hline January & ] 16,24$]$ & ]12, 16];]24, 28] & ] 8, 12];] 28, 32] & ] 5, 8];] 32, 35] & ] -, 5]; ] 35, +[ \\
\hline February & ] 17, 23] & ]14, 17];]23, 26] & ]10, 14];]26, 30] & ] 7, 10];] 30, 33] & ]-, 7];] 33, +[ \\
\hline March & ] 15,25$]$ & ]11, 15];]25, 29] & ] 6, 11];] 29, 34] & ] 2, 6];] 34, 38] & ] -, 2];] 38, +[ \\
\hline April & ] 20,30] & ] $14,20] ;] 30,36]$ & ] 9, 14];] 36, 41] & ] 4, 9];] 41, 46] & ] -, 4];] 46, +[ \\
\hline May & ] 20, 30] & ]15, 20];]30, 35] & ] 9, 15]; 35,41$]$ & ] 4, 9]; ] 41, 46] & ] -, 4];] 46, +[ \\
\hline June & ] 21, 29] & ]17, 21];]29, 33] & ]12, 17];]33, 38] & ] 8, 12]; ] 38, 42] & ]$-, 8] ;] 42,+[$ \\
\hline July & ] 20, 30] & ]15, 20];]30, 35] & ] 9, 15]; ]35, 41] & ]4, 9];] 41, 46] & ]-, 4];] 46,+[ \\
\hline August & ] 20, 30] & ]16, 20];]30, 34] & ]11, 16];]34, 39] & ]7, 11];] 39, 43] & ] -, 7];] 43, +[ \\
\hline September & ] 20, 30] & ]15, 20];]30, 35] & ]9, 15];]35, 41] & ]4, 9];] 41, 46] & ]-, 4];] 46, +[ \\
\hline October & ] 15,25$]$ & ]11, 15];]25, 29] & ]6, 11];] 29, 34] & ] 2, 6];] 34, 38] & ]-, 2];] 38, +[ \\
\hline November & ] 15,25 ] & ]10, 15];]25, 30] & ]4, 10];] 30, 36] & ] -1, 4];] 36, 41] & ]$-,-1] ;] 41,+[$ \\
\hline December & ] 16,24$]$ & ]12, 16];]24, 28] & ] 7, 12];] 28, 33] & ] 3, 7];] 33, 37] & ]-, 3];] 37, +[ \\
\hline
\end{tabular}

For the noise quality level, the classification presented in Table 2 is used.

The heat index depends on the month of the year, assuming quality levels from Very Poor to Very Good according to the classification system summarized in Table 3 (used for the case of Braga).

\section{The web-based monitoring and information system for Braga}

The evaluation of the urban environmental quality of a city has become a major concern to public authorities and especially for residents. At this point, the architecture of an urban system to monitor the air and noise for the city of Braga (Portugal) named smarBRAGA will be characterized, as well as the infrastructure of acquisition and analysis of the necessary data. To provide a global overview of the smarBRAGA project, some outputs and results of this monitoring and information to the public platform will be presented.

\subsection{The architecture of SmarBRAGA}

The SmarBRAGA is an information system for the public and the urban environmental monitoring system of the city of Braga. With this platform, Braga owns an innovative service of information to the public that can be considered pioneer in Portugal.

The SmarBRAGA project aims to inform the population about the central aspects of the urban environment, such as: noise, air quality and meteorology, as well as to create an infrastructure of acquisition, storage, processing and communication of data related with the urban environment. In a more detailed 
level, the specific objectives are to monitor the urban noise, the air quality and the meteorological data in the city, plus to store the digital cartography of the urban noise and of atmospheric pollutants, as well as to generate scenarios of noise and air pollution predictions, and finally to maintain a system of alert and information to the public on noise and on air quality.

For the development work, three infrastructures (Figure 1) were created, namely a web platform that integrates the services of acquisition and analysis of data, and information to the public; a technological solution of acquisition of environmental data constituted by two mobile units of acquisition and collection of data; and an analysis centre for the development and deployment of scenarios for long term periods.

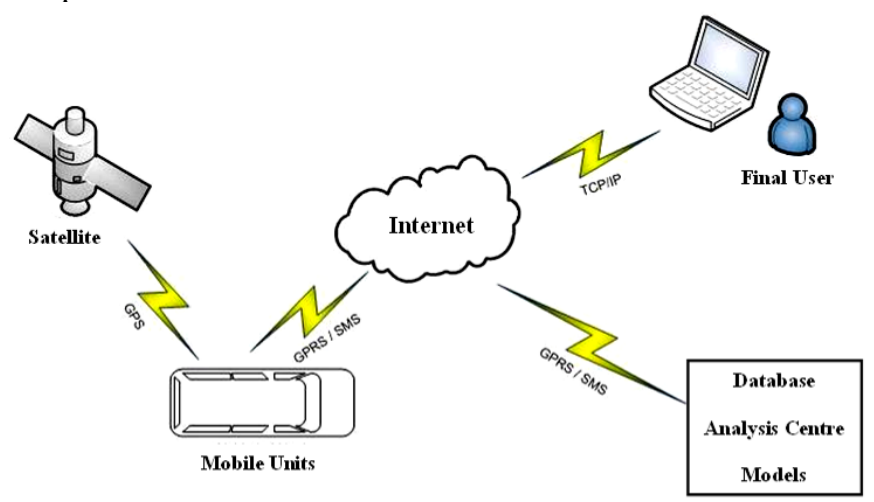

Figure 1: Overall functioning scheme of SmarBRAGA.

The SmarBRAGA project elapsed throughout 2007 and 2008, and it is foreseen that the availability of the service to the general public will start by the Summer of 2009. The global process of the project was established in four group stages, namely the equipment and hardware acquisition, the development work, the testing stage and the training and start-up.

\subsection{The data acquisition and analysis infrastructure}

Besides the human resources, in this project the following material resources were used: modified and adapted mobile units, GPS receptors, digital sound measurements, meteorological stations, particles and other air pollutant measuring equipments, simulation software for air pollution and noise prediction, among others.

The mobile units (Figure 2) take measurements in a specific location of the city (GPS technology), and transmit them through wireless communication for the web platform. On board of the mobile units are installed the modules for noise, air pollution, meteorological, multimedia, communication and positioning, even though this complete set is not always necessary for a particular measurement.

The aim of the analysis centre is to develop and provide the long term scenarios (in the form of maps) of the noise and the atmospheric pollution 


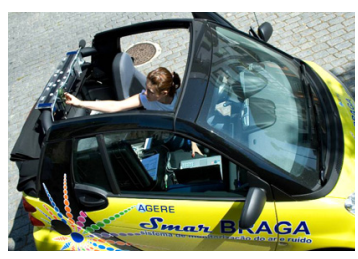

a) Mobile unit in operation

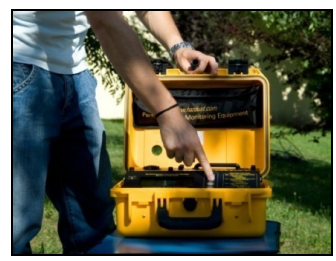

b) Measurement of particles in loco

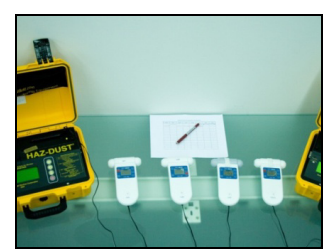

c) Recharging the batteries of several sensors

Figure 2: Examples of the functioning of data acquisition infrastructure.

through the web platform, as well as traffic statistics. For this purpose, the corresponding technological solution includes: i) the software for noise prediction with a traffic module based on the Directive 2002/49/CE and with the capacity to deal with mid/large cities; ii) the software for air pollution simulation, which integrates with the noise software; iii) and two high performance computers.

The software used in this case was CadnA, which integrates both components (noise and air pollution) and thus allows to rationalise the effort associated with data maintenance related with three-dimensional urban characteristics and traffic information, usually necessary to built urban databases for modelling noise and atmospheric pollution. Figure 3 shows some pictures of the analysis centre.

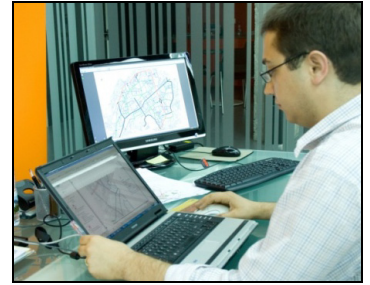

a) Simulation software in use

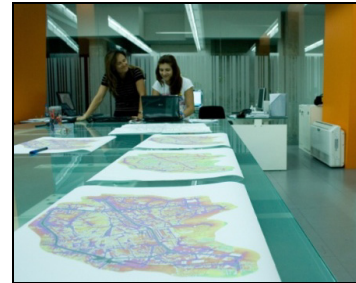

b) Layout of information produced

Figure 3: Analysis centre in operation.

\subsection{Examples of results}

The results of SmarBRAGA project are mainly available on the web platform of information to the public. This platform aims to automatically process and provide information, integrating data acquired in real or differed time, as well as the long term simulations, through a user-friendly interface and innovative technologies of representation and mapping. This is structured in five channels, as follows:

The Homepage of SmarBRAGA. Includes a synthesis of up-to-date information, through a system of classification and information to the public based on colour quality labels, ranging from green to red (Figure 4). 


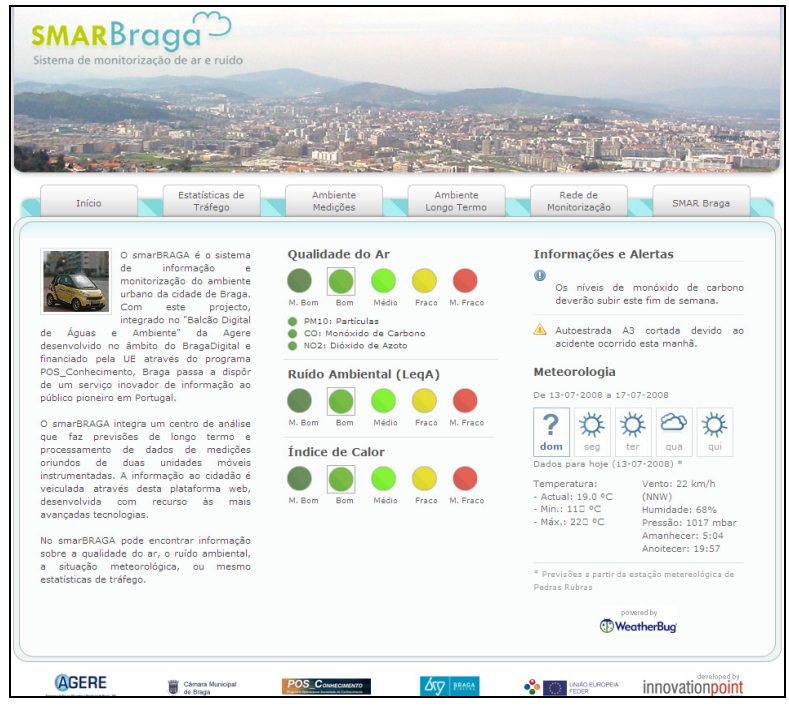

Figure 4: $\quad$ SmarBRAGA: homepage.

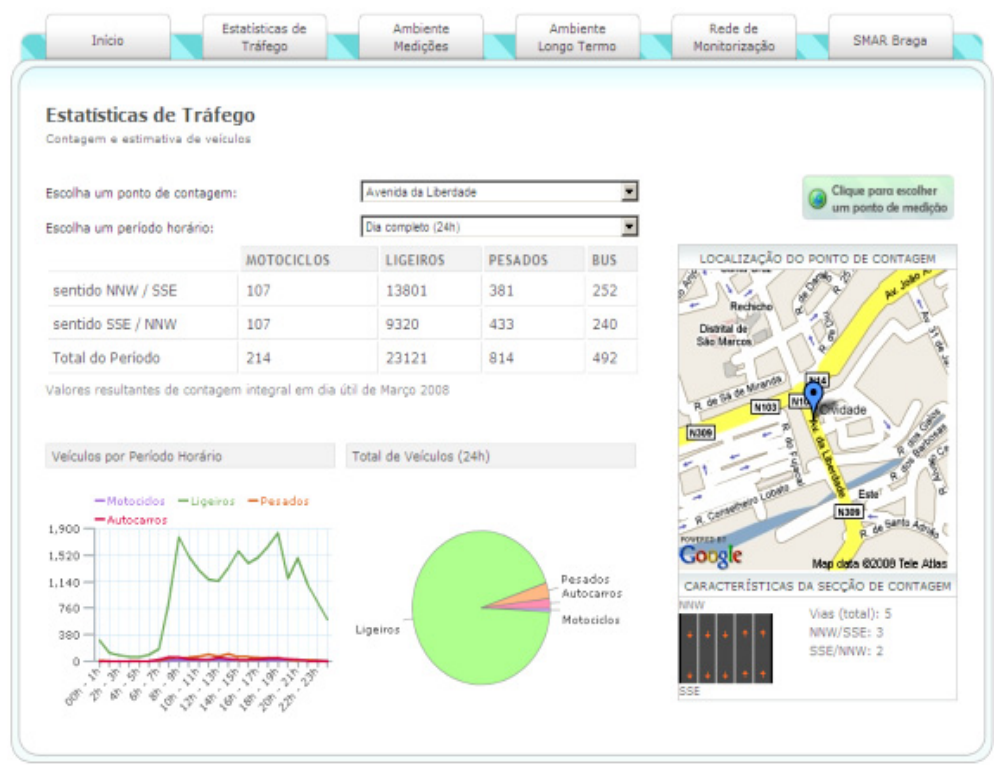

Figure 5: SmarBRAGA: traffic statistics.

Traffic statistics. The available data resulted from a traffic counting campaign (by category of vehicles) carried out in 2008 on the road network of Braga. These data are associated with specific periods of time; however the platform can be developed to integrate on-line information of traffic (Figure 5). 
Long-term environment. Long-term environmental maps of noise and air pollution are available together with navigation tools developed over Google Maps technology (Figure 6).

Environmental measurements. The measurements of environmental and meteorological parameters are integrated automatically after its acquisition through the mobile units in the monitoring network points.

Monitoring network. Points of measurement that are part of the monitoring network are represented in a map with navigation functionalities and satellite image reference, as well as cross-links for information of measurements and environmental quality.

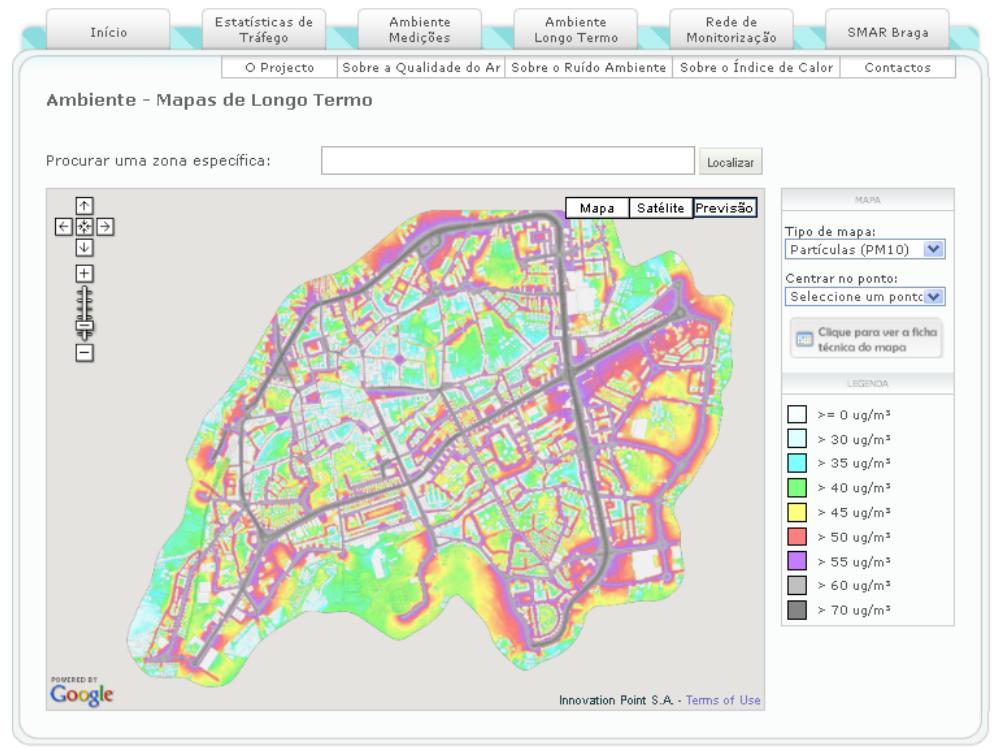

Figure 6: $\quad$ SmarBRAGA: Long-term $\mathrm{PM}_{10}$ concentrations map.

\section{Conclusions}

The aim of a monitoring and information system is to support the formulation of control strategies and, additionally, to inform the population about the urban environmental situation. This paper focused on the information objective.

A conceptual model for the urban environmental information system was presented. The critical aspects identified for such an information system were: i) the quality label-based information; ii) the long-term environmental maps versus the point-measurements; iii) the importance of motor traffic as the main pollution source; iv) the selection of air pollution and noise descriptors; and v) the algorithm which generates environmental quality labels. 
Based on this conceptual outline, a web-based information system was developed for the city of Braga, in Portugal. The so-called SmarBRAGA project aims at informing the population about the central aspects of the urban environment, such as: noise, air quality and meteorology. For this purpose an infrastructure of acquisition, storage, processing and communication of data was created.

The web-based platform SmarBRAGA includes a home page where almostreal time environmental information is presented and classified through quality labels. Dedicated channels in this platform include information on traffic, pointmeasurements, long-term pollution maps, and the monitoring network.

\section{References}

[1] OECD, (eds). Roadside Noise Abatement, Organisation for Economic Cooperation and Development Publications: Paris, France, 1995.

[2] Silva, L.T., Avaliação da Qualidade Ambiental Urbana. PhD Thesis, Universidade do Minho, Braga, Portugal, 2008.

[3] Mendes, J.F.G.; Silva, L.T., Evaluating critical noise disturbance zones in a mid-sized city. International Conference on Sustainable Planning \& Development, 2003.

[4] Mendes, J.F.G.; Silva, L.T., Evaluating conflict zones of air pollution in a mid-sized city. International Conference on Sustainable Planning \& Development, 2007.

[5] Highways Agency. Design Manual for Road and Bridges Volume 11, Section 3, Part 1 - Air Quality, UK, 2003

[6] Silva, L.T., Mendes, J.F.G. Determinação do índice de qualidade do ar numa cidade de média dimensão. Engenharia Civil. 27, p. 63-74, 2006.

[7] Decreto-Lei $n^{\circ}$ 9/2007 de 17 de Janeiro. Diário da República, I Série-A, Lisboa, Portugal, 2007. 